\title{
Significância de anticorpos vibriocidas circulantes em área pós-epidêmica de diarréia, São Bento do Una, Estado de Pernambuco
}

\author{
The importance of circulating vibriocidal antibodies in a pos-epidemic \\ region of diarrhea, São Bento do Una, State of Pernambuco \\ Lúcia Roberta de Souza Filizola ${ }^{1}$, Ângela Cristina Torres de Araújo Figueirôa ${ }^{1}$,

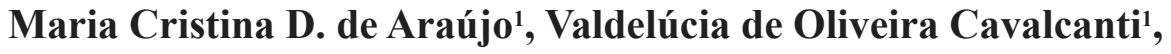 \\ Cristiani Maria de Lima ${ }^{1}$ e Ernesto Hofer ${ }^{2}$
}

\begin{abstract}
RESUMO
Verificou-se o nível de anticorpos vibriocidas em 41 indivíduos adultos, sem história passada ou presente de diarréia por Vibrio cholerae $O_{p}$, residentes no município de São Bento do Una, Pernambuco. Nessa localidade ocorreu no início de 2004 um surto de diarréia, com múltiplos agentes bacterianos envolvidos, incluindo o vibrião colérico. Foi empregado o teste da microtitulação de anticorpos séricos vibriocidas, antiOgawa e anti-Inaba, considerando-se como indicativo de infecção por Vibrio cholerae $O_{p}$, os títulos vibriocidas $\geq 1: 640$. A freqüiência dos reagentes foi de 36 (87,8\%) para o sorovar Ogawa, o que evidencia a possível circulação do vibrião colérico, durante e/ou após a epidemia de diarréia.
\end{abstract}

Palavras-chaves: Cólera. Vibrio cholerae $O_{r}$. Anticorpos vibriocidas.

\begin{abstract}
The levels of vibriocidal antibodies were investigated among 41 adults without any past or present history of diarrhea due to Vibrio cholerae $O_{1}$ who were living in the municipality of São Bento do Una, Pernambuco. A diarrhea outbreak occurred in this locality at the beginning of 2004, involving multiple bacterial agents, including Vibrio cholerae. The microtitration test was used to investigate the presence of anti-Ogawa and anti-Inaba vibriocidal serum antibodies. Vibriocidal titers $e^{\prime \prime}$ 1:640 were considered indicative of infection by Vibrio cholerae $O_{I}$. The frequency of the reagents was 36 (87.8\%) for the Ogawa serovar, which showed that Vibrio cholerae $O_{1}$ was possibly circulating during and/or after the diarrhea epidemic.
\end{abstract}

Key-words: Cholera. Vibrio cholerae $O_{r}$. Vibriocidal antibodies.

Vários métodos laboratoriais são utilizados para verificar a resposta imune na infecção humana provocada pelo vibrião colérico. Alguns processos se caracterizam pela simplicidade de execução, mas com a devida sensibilidade e especificidade em revelar os anticorpos resultantes da sensibilização do hospedeiro contra os antígenos somáticos, como no caso da aglutinação e da capacidade vibriocida. Esse último teste evidencia a ação bactericida do anticorpo somático em presença de complemento sobre a bactéria ${ }^{5}$.

A prova dos anticorpos vibriocidas é mais sensível que a aglutinação, detectando anticorpos específicos que podem estar presentes em diferentes estágios da doença e/ou infecção colérica (fase aguda e convalescente), além de ser aplicada no diagnóstico retrospectivo da cólera em áreas endêmicas ou não. Isso decorre da propriedade que os títulos dos anticorpos vibriocidas persistem por 6 a 12 meses com retorno a níveis anteriores à infecção após 13 a 19 meses $^{369}$.

É interessante que nas áreas não endêmicas, pequena parcela da população (<15\%, em todas as idades) apresentaram anticorpos vibriocidas naturais, provavelmente provenientes da exposição de outros microrganismos (Brucella e Enterobactérias) ${ }^{15719}$.

Com base nos estudos prévios sobre um surto de diarréia, que comprometeu parte da população de São Bento do Una, Pernambuco, no período de março a junho de 2004,

\footnotetext{
1. Laboratório Central de Saúde Pública Dr. Milton Bezerra Sobral, Recife, PE. 2. Laboratório de Zoonoses Bacterianas, Instituto Oswaldo Cruz, Fundação Oswaldo Cruz, Rio de Janeiro, RJ.

Endereço para correspondência: Dr. Ernesto Hofer. Lab. Zoonoses Bacterianas/FIOCRUZ. Av. Brasil 4365, Manguinhos, $21040-900$ Rio de Janeiro, RJ.

Tel: 5521 2598-4277 ramal 332; Fax: $55212270-6565$

e-mail: ernesto.hofer@yahoo.com.br

Recebido para publicação em: 14/05/2007

Aceito em: 11/10/2007
} 
foram detectadas várias bactérias enteropatogênicas. No acontecimento chamou atenção a discreta ocorrência de Vibrio cholerae $0_{1}$ sorovar Ogawa entre os indivíduos com processos diarréicos ${ }^{12}$. Essa situação epidemiológica, motivou a presente investigação, concentrada na análise do nível de anticorpos vibriocidas em um pequeno contingente da população da cidade, após seis meses da ocorrência do surto.

As 41 amostras sangüíneas foram obtidas por punção venosa periférica, utilizando-se tubos vacuteiner, durante outubro de 2004. As coletas foram realizadas nas visitas domiciliares, aleatórias, nas quais a decisão de participar do estudo coube a cada doador ou seu responsável, após esclarecimento da natureza e dos objetivos da pesquisa. No momento da visita, dados referentes as condições de abastecimento de água, destino dos dejetos e do lixo foram anotados.

Todas as amostras de sangue colhidas e imediatamente encaminhadas para o Laboratório Central de Saúde Pública do Estado de Pernambuco (LACEN/PE), Recife, onde foram centrifugadas e separadas as frações séricas e mantidas a $-20^{\circ} \mathrm{C}$ até o processamento laboratorial definitivo.

As amostras séricas se originaram de residentes dos seguintes bairros ou localidades da cidade: Delmário Braga (2), Iraque (4), Rua da Pedra (10), Santo Afonso II (10), Bairro Novo (4) e Centro (11). 0 grupo etário predominante foi de 21 a 30 anos constituído de 14 indivíduos $(34,1 \%)$ tendo em sequiência a seguinte ordem: 11 a 20 anos (9-21,9\%), 31-40 anos (8-19,5\%), 41 a 50 anos (4-9,7\%) e de $\geq 51$ anos (6-14,6\%). Entre os participantes, 29 indivíduos (70,7\%) mencionaram a ocorrência de episódios diarréicos nos últimos 12 meses, mas, sem que tenha tido a confirmação laboratorial de isolamento de Vibrio cholerae $0_{1}$. Como grupo controle foram incluídas as amostras séricas de indivíduos adultos, residentes na cidade do Rio de Janeiro, coletadas em outubro de 2004.

Pesquisa de anticorpos vibriocidas. Utilizou-se o método de microtitulação, de acordo com a técnica descrita por Benenson $\mathrm{cols}^{2}$ e com as modificações propostas por Dodin \& Fornier ${ }^{4}$. As diluições seriadas em salina tamponada do soro sangüíneo (1:5 a 1:2560) foram depositadas nas cavidades da microplaca estéril com fundo em "U", nas quais, adicionam-se as suspensões padronizadas das bactérias vivas (Vibrio cholerae $0_{1}$ sorovar Ogawa - VC-12 e Vibrio cholerae $0_{1}$ sorovar Inaba - VC-13 da coleção do Laboratório de Referência Nacional de Cólera, IOC/ FIOCRUZ). As suspensões apresentando turbidez similar ao tubo $\mathrm{n}^{0} 1$ da escala de Mac Farland, correspondendo a aproximadamente a $3 \times 10^{8} \mathrm{UFC} / \mathrm{mL}$ foram misturadas a um excesso de complemento (Sigma). A adição dessa mistura as cavidades da placa com os soros, em volumes iguais, determinou a duplicação dos títulos iniciais para $1: 10$ a $1: 5120$. Após a incubação a $37^{\circ} \mathrm{C}$ por 1 hora do sistema, foram adicionadas nas cavidades pequenos volumes de Água Peptonada Alcalina, $\mathrm{pH}$ 8.0-8.2 e reincubando-se por mais duas horas a $37^{\circ} \mathrm{C}$. Finalmente, como revelador de crescimento bacteriano incorporou-se nas cavidades, uma solução a 1\% de cloridrato de tetrazólio (Difco). Após a manutenção do sistema por 15 minutos à temperatura ambiente, efetuou-se a leitura provisória e após uma noite em geladeira, foi realizada a leitura definitiva. Na presença de células viáveis observa-se a redução do tetrazólio para formazana, composto violeta (cavidades com turbidez e botões de crescimento corados). Aquelas cavidades com fluído transparente, incolor, indica a lise das bactérias por ação dos anticorpos.

0 título final está representado pela última diluição em que a cavidade não tenha crescimento bacteriano (sem depósito e transparência do meio) e qualquer dúvida na interpretação dos resultados implicou na repetição do teste. Ainda como controles foram incluídos um anti-soro $0_{1}$ de Vibrio cholerae (positiva), um soro de coelho (negativo) e as verificações da ação do complemento, de antígenos de formas lisas de Vibrio cholerae e os comportamentos do meio de cultura e do tetrazólio ${ }^{24}$.

Diante da grande variabilidade de títulos indicativos da infecção pelo vibrião colérico na literatura $(1: 40$ até 1:1280) 2357891314 , adotou-se como título de referência $\geq 1: 640$, considerando-se as circunstâncias epidemiológicas de um período de tempo curto de pós-surto.

Nos 41 soros analisados, $36(87,8 \%)$ e $17(41,4 \%)$ apresentaram títulos vibriocidas $\geq 1: 640$, em presença dos antígenos Ogawa e Inaba, respectivamente. Em contraposição, nos títulos inferiores ao de referência, incluindo os não reagentes, predominaram aqueles com 0 antígeno Inaba (24-58,5\%) contra $5-12,1 \%$ de Ogawa (Tabela 1).

Tabela 1 - Freqüência dos títulos de anticorpos vibriocidas (Ogawa e Inaba) em 41 doadores da Cidade de São Bento do Una, Estado de Pernambuco.

\begin{tabular}{|c|c|c|c|c|}
\hline \multirow[t]{2}{*}{ Títulos } & \multicolumn{2}{|c|}{ Ogawa } & \multicolumn{2}{|c|}{ Inaba } \\
\hline & $\mathrm{n}^{0}$ & $\%$ & $\mathrm{n}^{0}$ & $\%$ \\
\hline Não reagente & 1 & 2,4 & 12 & 29,2 \\
\hline 1:10 & - & - & 5 & 12,1 \\
\hline $1: 20$ & 1 & 2,4 & 2 & 4,8 \\
\hline 1:40 & 2 & 4,8 & 2 & 4,8 \\
\hline $1: 80$ & 1 & 2,4 & 2 & 4,8 \\
\hline $1: 160$ & - & - & 1 & 2,4 \\
\hline $1: 320$ & - & - & - & - \\
\hline $1: 640$ & - & - & 2 & 4,8 \\
\hline 1:1280 & 1 & 2,4 & - & - \\
\hline $1: 2560$ & 1 & 2,4 & 1 & 2,4 \\
\hline 1:5120 & 34 & 82,9 & 14 & 34,1 \\
\hline
\end{tabular}

Salienta-se que os resultados obtidos através da utilização de dois antígenos elevaram o nível de sensibilidade do teste, tal qual Clements e cols ${ }^{3}$ e Mosley ${ }^{14}$ tiveram oportunidade de referir, inclusive minimizando a interferência cruzada de anticorpos naturais, oriundos de outros agentes bacterianos ${ }^{1519}$.

Um outro aspecto que chama atenção nos resultados é 0 número de soros com atividade vibriocida elevada sobre 0 sorotipo Inaba. Admite-se como hipótese para o fenômeno que Vibrio cholerae 0, Ogawa circulante na fase do surto de diarréia induziu a produçã̃o de anticorpos tanto para Ogawa como Inaba, considerando as observações nesse sentido de Mosley ${ }^{14}$. Além do mais, os estudos soro-epidemiológicos realizados por Gonçalves e cols ${ }^{11}$ e Gonçalves ${ }^{8}$, em Manacapuru, Amazonas e em São Luís, Maranhão, evidenciaram anticorpos vibriocidas tanto para Ogawa 
como Inaba em populações que tinham sido comprometidas pela cólera, cinco anos antes, apenas pelo sorotipo Inaba. Assinala-se ainda, o reconhecimento em copépodes de ambiente aquático de São Luís, de Vibrio cholerae $0_{1}$ viável, mas não cultivável $^{10}$, que até certo ponto explica a circulação silente da bactéria em diferentes fontes e vias de transmissão. Quanto a Pernambuco, uma das áreas mais comprometidas pela cólera no nordeste na década de 90 do século passado, não ocorreram casos humanos desde 2001. No entanto, entre 2002 e 2004 foram isolados de meio ambiente Vibrio cholerae 0 Ogawa não toxigênica nos municípios da Camaragibe, Caruaru e Macaparana (E Hofer: dados não publicados) e que provavelmente, poderiam explicar a sensibilização imune constante em algumas áreas.

Outras explicações podem ser aduzidas como a presença da fração antigênica $C$, na variação entre Ogawa e Inaba, tendo em vista que Sakazaki \& Tamura $^{16}$, demonstraram que o sorovar Inaba descendia de Ogawa após a perda da fração B. A reversão inversa não ocorre, isto é, Inaba para Ogawa. Segundo os mesmos autores, não é tão raro detectar uma ou mais colônias do sorovar Inaba entre muitas Ogawa nas coproculturas de pacientes com cólera e admitem que essa dissociação antigênica tenha ocorrido no intestino do indivíduo colérico. É interessante que num trabalho antigo de 1947, Shrivastava \& White ${ }^{17}$, descreveram a variação dos antígenos somáticos de Ogawa para Inaba em meio contendo aglutinina anti-Ogawa. Sem dúvida as duas experiências favorecem as hipóteses formuladas para a ocorrência de títulos elevados de anticorpos vibriocidas anti-Inaba na amostragem sérica analisada.

A prevalência da infecção colérica em São Bento do Una, nesta pequena amostragem pode ser estimada como elevada, caracterizando que a disseminação do vibrião foi mais ampla do que se poderia supor, tendo em vista o número discreto de casos diagnosticados laboratorialmente durante o surto de diarréia ${ }^{12}$. Aliás, esse resultado assemelha-se àquele verificado no Peru ${ }^{18}$ em comunicantes de casos-índices, e que se respalda nos argumentos de Nalin cols ${ }^{15}$ ao afirmarem que quando um caso-índice é reconhecido numa localidade, a infecção já se disseminou amplamente, oscilando a taxa de caso/infecção entre 1:30 - 100, com o biotipo El Tor.

Considerando que passados mais de seis meses da ocorrência do surto, os títulos elevados de anticorpos vibriocidas detectados, talvez expressem uma resposta a possível re-exposição da população ao vibrião colérico, o que compatibiliza com a opinião de Finkelstein ${ }^{6}$. Sem dúvida que a disseminação da bactéria sempre esteve envolvida com o meio ambiente, principalmente através da veiculação hídrica, tendo em vista que o abastecimento público de água, escasso e intermitente inclusive sem o teor residual de cloro nos pontos terminais (residências). Nessa circunstância a população recorreu ao uso de água de cisterna e de fontes alternativas de abastecimento (barreiros, carros pipa), sem o menor controle sanitário e microbiológico. Associado ao problema, cita-se como fator importante as deficiências do esgotamento sanitário em alguns bairros da cidade, exemplificando-se a falta de manutenção das fossas, com frequiência extravasando efluentes não tratados para o meio ambiente (valas a céu aberto) ou ainda, destinando os dejetos diretamente para o rio $\mathrm{Una}^{12}$.

Quanto a outros aspectos, salienta-se que não se verificou a influência dos grupos etários superiores a 30 anos no aumento acumulativo dos títulos vibriocidas como foi referido por Mosley ${ }^{14}$ nas áreas endêmicas. Na presente investigação os títulos 1:640 com antígeno Ogawa foram reconhecidos de forma homogênea em todas as faixas etárias, tendo como média $87,9 \%$. De forma similar considerando os bairros das residências dos doadores, tanto naqueles em que ocorreram os 18 casos de cólera ${ }^{12}$, diagnosticados laboratorialmente (Delmário Braga, Iraque, Rua da Pedra, Santo Afonso II e Bairro Novo) como na área do centro da cidade, sem isolamento do vibrião, com a população mais numerosa e onde foi registrada a menor taxa de ataque de casos de diarréia, o nível de anticorpos vibriocidas 1:640, apresentou a média de $87,8 \%$ de reagentes.

Com os resultados ora disponíveis, admite-se que serão necessários novos estudos em futuro próximo, não só na área em questão como em outras regiões de Pernambuco, no sentido de avaliar a circulação da bactéria e o nível de infecção colérica na população.

\section{AGRADECIMENTOS}

Ao pessoal técnico das Vigilâncias Sanitária e Epidemiológica das Secretarias de Saúde do município de São Bento do Una e do Estado de Pernambuco, pela adesão e participação no trabalho. Às Dras. Nancy Veloso de Lima e Ana Maria de Lima Barros pelo apoio prestado. Aos técnicos da Epidemiologia da Secretaria de Saúde: Sonia Maria Alencar e Maria de Fátima Henriques Correia e do Instituto Oswaldo Cruz, RJ, à Darcília Maria de Andrade.

\section{REFERÊNCIAS}

1. Barua D, Watanabe Y. Vibriocidal antibodies induced by Yersinia enterocolitica serotype IX. The Journal of Hygiene 70: 161-169, 1972.

2. Benenson AS, Saad A, Mosley WH. Serological studies in cholera. 2. The vibriocidal antibody response of cholera patients determined by a microtechnique. Bulletin of the World Health Organization 38: 277-285, 1968.

3. Clements, ML, Levine MM, Young CR, Black RE, Lim YL, Robins-Browne RM, Craig JP. Magnitude, kinetics and duration of vibriocidal antibody responses in North Americans after ingestion of Vibrio cholerae. Journal of Infectious Diseases 145: 465-472, 1982.

4. Dodin A, Fornier JM. Technique sérologique: etude du pouvoir vibriocide. In: Dodin A, Fornier JM (eds) Méthodes de Laboratoire pour le Diagnostic du Vibrion Cholérique et des Autres Vibrions, Institut Pasteur, France, p. 41-47, 1992.

5. Feeley JC, De Witt WE. Immune response to Vibrio cholerae. In: Rose NR, Friedman H (eds) Manual Clinical Immunology. $1^{\text {st }}$ edition, American Society for Microbiology, Washington DC, p. 289-295, 1976.

6. Finkelstein RA. Cholera. Critical Reviews in Microbiology 2: 553-623, 1973.

7. Gangarosa EJ, De Witt WE, Feeley JC, Adams MR. Significance of vibriocidal antibodies with regard to immunity to cholera. Journal of Infectious Diseases 121 (suppl): S36-S44, 1970.

8. Gonçalves EGR. Vibrio cholerae: estudo da associação com o zooplâncton de águas estuarinas da Baía de São Marcos-São Luís (MA). Tese de Doutorado, Instituto Oswaldo Cruz/Fundação Oswaldo Cruz, Rio de Janeiro, RJ, 2001. 
9. Gonçalves EGR, Hofer E. Análise dos anticorpos vibriocidas e aglutinantes na população urbana do município de Manacapuru/AM (1992/1993). Revista da Sociedade Brasileira de Medicina Tropical 31: 187-192, 1998.

10. Gonçalves EGR, Lopes MJS, Oliveira EG0, Hofer E. Associação de Vibrio cholerae com o zooplâncton de águas estuárias da Baía de São Marcos/São Luís-MA, Brasil. Revista da Sociedade Brasileira de Medicina Tropical 37: 318-325, 2004.

11. Gonçalves EGR, Sabroza PC, Hofer E. Prevalência de infecção por Vibrio cholerae $\mathrm{O}_{1}$ no município de Manacapuru, Amazonas, Brasil. Cadernos de Saúde Pública 14: 319-352, 1998.

12. Hofer E, Reis CMF, Theophilo GND, Cavalcanti VO, Lima NV, Henriques MFCM. Envolvimento de Aeromonas em surto de doença diarréica aguda em São Bento do Una, Pernambuco. Revista da Sociedade Brasileira de Medicina Tropical 39: 217-220, 2006.

13. Khan MV, Barua DK, Begun T, Shahidrullah M. Vibriocidal titre in cholera case and contacts: it's value in assessing endemicity of or susceptibility to cholera. Tropical and Geographical Medicine 39: 271-275, 1987.
14. Mosley WH. The role of immunity in cholera. A review of epidemiological and serological studies. Texas Reports on Biology and Medicine 27: 227-241, 1969.

15. Nalin DR, Morris Jr JG. Cholera and other vibrioses. In: Strickland GT (ed) Hunter's Tropical Medicine, $7^{\text {th }}$ edition, WB Saunders Company, Philadelphia, p. 366-375, 1991.

16. Sakazaki R, Tamura K. Somatic antigen variation in Vibrio cholerae. Japanese Journal of Medical Science and Biology 24: 93-100, 1971.

17. Shrivastava DL, White PB. Note on the relationship of the so-called Ogawa and Inaba types of V. cholerae. Indian Journal of Medical Research 35: 117-129, 1947.

18. Swerdlow DL, Mintz EE, Rodriguez M, Tejada E, Ocampo C, Espejo L, Greene KD, Saldana W, Seminario L, Tauxe RV, Wells JG, Bean NH, Ries AA, Polack M, Vertiz B, Blake PA. Waterborne transmission of epidemic cholera in Trujillo, Peru: Lesson for a continent at risk. Lancet 340: 28-32, 1992.

19. Varela G, Del'Acqua L, Hortal M. Determinación de anticuerpos bactericidas dirigidos contra Vibrio cholerae en una población de adultos de Montevideo. Revista Argentina de Microbiologia 27: 185-190, 1995. 